\title{
Temperature influence on strain state of a flexible plate
}

\author{
Tatiana Treputneva ${ }^{1, *}$, Oleg Popov ${ }^{1}$, Margarita Moiseenko ${ }^{1}$, Vladislav Maksak ${ }^{1}$, Anatoly \\ Malinovskiy ${ }^{1}$, and Nikita Mescheulov ${ }^{1}$ \\ ${ }^{1}$ Tomsk State University of Architecture and Building, 634003 Tomsk, Russia
}

\begin{abstract}
Developing analytical methods for studying the strain state of flexible plates is a relevant issue, especially for complex problems that recognize nonlinear operation and temperature-dependent changes in mechanical properties of materials. The paper analyzes the stress-strain state of a two-field flexible plate with an initial deflection exposed to a non-uniform temperature field. It presents and analyzes the results of the numerical studies based on an algorithm developed by the authors for designing anisotropic rectangular structural elements with discontinuous parameters, taking into account nonlinearities. The analysis of the design results suggests that initial deflection, physical and geometric nonlinearities, as well as inhomogeneity of the plate material need to be taken into consideration.
\end{abstract}

\section{Introduction}

Plates and shells are the basic structural elements that are exposed to power loads and temperatures during their operation $[1-8,10]$. High-temperatures influence leads to a change in mechanical properties of the material and causes a decrease in structural rigidity $[4,5]$. Imperfections in the initial shape of the structural surface (initial deflections) lead to qualitative differences in the stress-strain state as compared to a design model $[6,7]$. Therefore, it is important to study the stress-strain state of flexible plates with an initial deflection taking into account temperature-dependent changes in mechanical properties of the material. A review of publications in this area also points to the importance of this study.

V. P. Kruglov [3] investigated the load-bearing capacity of flexible steel plates taking into account changes in mechanical properties of the material. A. G. Tamrazyan and A. S. Kozhanova [4] demonstrated high-temperature effects on thermal creep of shallow reinforced concrete shells and flat plates. Pham T. M., et al [11] investigated the influence of eccentric loading on the load-bearing capacity of reinforced concrete columns. Zhang Y. and Karr D. G. [12] developed analytical models to design plates under quasi-static pressure. The pressure in the plate arises from the contact with lake ice, which is caused mainly by thermal expansion and winds. Bhat S.U., Choi S.K., Wierzbicki, Karr D.G. investigated a dynamic response of a ship interacting with an ice floe [13].

\footnotetext{
* Corresponding author: mmo77@mail.ru
} 
However, there are only a few publications that analyze nonlinear strain of plates with due regard to the combined effect of initial deflection, physical and geometric nonlinearity and temperature-dependent changes in mechanical properties $[3,4,11]$. Therefore, this issue needs to be further studied.

The purpose of this paper is to study temperature-dependent changes in the stress-strain state of the plate. The studies are based on a previously developed mathematical model for designing flexible plates with an initial deflection that are exposed to certain temperatures [9]. The model takes into account anisotropy, heterogeneity and change in physical characteristics of the material under the influence of temperature.

\section{Design Model and Algorithm}

The model of the structure under consideration is a two-field plate with thickness $h=1 \mathrm{~cm}$ that consists of square panels $(a=b=50 \mathrm{~cm})$ and is placed in a non-uniform temperature field. The material of the structure is VT6 (titanium wrought alloy) [1]. The plate has a symmetrical initial deflection $W_{n}$ and rigidly hinged along the contour and the center (Fig. 1).

In order to assess the stress-strain state of the structure more completely, it was designed with due regard to double nonlinearity (physical and geometric), initial deflection and temperature-dependent mechanical properties of the material.
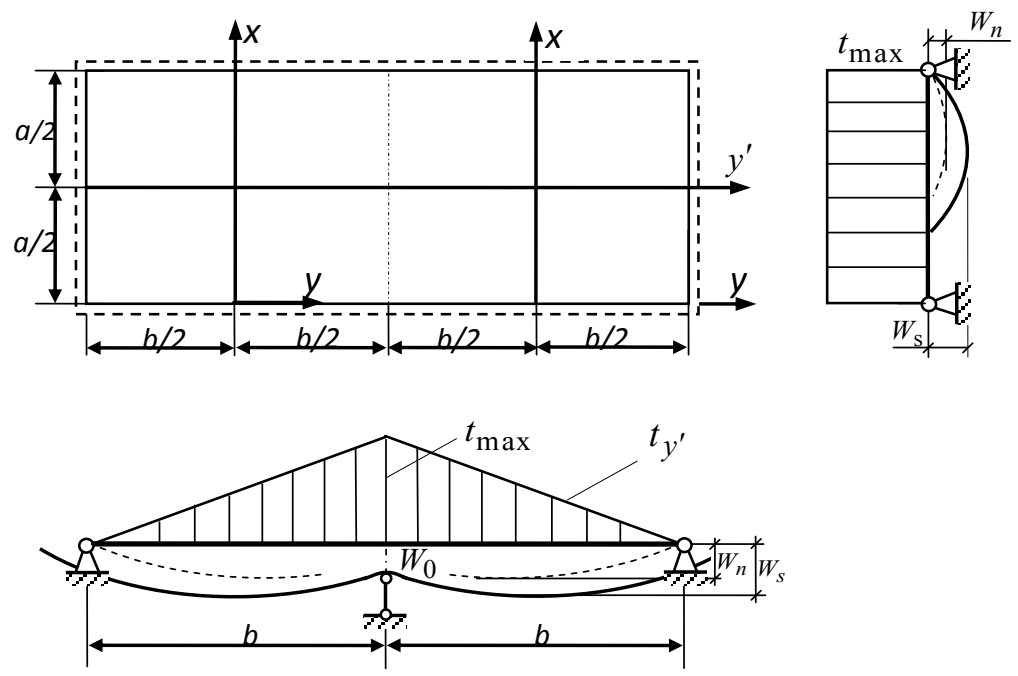

Fig. 1. A two-field flexible plate exposed to a variable temperature field.

This study uses the Goldenblat-Nikolayenko model [1] to take into account temperature-dependent properties of the material by constructing polynomial approximating dependence graphs.

The temperature across the panel field $k$ varies according to the relationship:

$$
t_{y^{\prime}}=(-1)^{k-1} \frac{y+b / 2}{b} \cdot t_{\max } .
$$

The initial deflection $W_{n}$ can be expressed as $W_{n}(x, y)=W_{0} F_{1}(x) F_{2}(y)$. 
Here $\quad F_{1}(x)=\sin \pi x, \quad$ where $\quad(0 \leq \bar{x} \leq 1) ; F_{2}(y)=\sin 0.25 \pi(1+\eta y), \quad$ where $(-1 \leq \bar{y} \leq 1) ; \eta=1$ at $k=1 ; \eta=-1$ at $k=2(k$ is the panel number $) ; W_{0}$ is the maximum initial deflection of the plate center: $W_{0}=0 ; h / 2 ; h . W_{s}$ is the total displacement of the plate obtained by summing the initial deflection $W_{n}$ and additional displacement of the plate $W$ induced by temperature.

In order to take into account changes in physical properties, geometric nonlinearity and additional displacements, the energy method can be applied together with the displacement model [7-9].

Nodal lines are introduced along the lines of intersection between the middle surface of the plate and the vertical inertial plane of the principal edges. In the general case, each nodal line has four functional unknown displacements. The coefficients for functional displacements are chosen so that they ensure compatible displacements of the articulated panels [7-9].

Components of middle panel surface strains $\varepsilon_{x}, \varepsilon_{y}, \varepsilon_{x y}$ and curvature $\chi_{x}, \chi_{y}$ are expressed through displacements $U, V, W$ along axes $x, y, z$, respectively, by the following relationships:

$$
\varepsilon_{x}=\frac{\partial U}{\partial x}+\frac{1}{2}\left(\frac{\partial\left(W+W_{H}\right)}{\partial x}\right)^{2}-\frac{1}{2}\left(\frac{\partial W_{H}}{\partial x}\right)^{2}-k_{1} W \quad \chi_{x}=-\frac{\partial^{2} W}{\partial x^{2}} \quad(x \leftrightarrow y)
$$

Here: $k_{1}, k_{2}$ are panel curvatures; $W_{H}$ is the initial deflection of the middle surface.

The relative strains of the panels $\varepsilon_{x o}, \varepsilon_{y o}, \varepsilon_{x y o}$ at the points located at a distance $z$ from the middle surface are written as:

$$
e_{x o}=\varepsilon_{x}+z \chi_{x} ; e_{x y o}=\varepsilon_{x y}+2 z \chi_{x y} \cdot(x \leftrightarrow y)
$$

The centers of gravity of the cross sections and torsion angles of the edges can be expressed using the Kirchhoff-Klebsch hypothesis [6]:

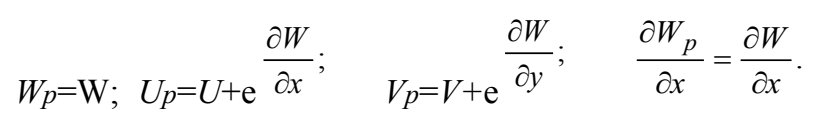

The strains along the edges $\varepsilon_{x p}, \varepsilon_{y p}$ are written taking into account eccentricity $e$ of the edges:

$$
\varepsilon_{x p}=\varepsilon_{x o}+e \chi_{x} . \quad x \leftrightarrow y .
$$

The relative strains of the edges $e_{x p}, e_{y p}, e_{z y p}, e_{z x p}$ are written taking into account bending in two planes, longitudinal strain and torsion:

$$
e_{x p}=\varepsilon_{x p}-z \frac{\partial^{2} W_{p}}{\partial x^{2}}-y \frac{\partial^{2} V_{p}}{\partial x^{2}} ; e_{z y p}=e_{z x p}=\frac{\partial^{2} W_{p}}{\partial x \partial y} . \quad x \leftrightarrow y .
$$

The stresses are expressed through strains, taking into account the temperature load on the panel:

$$
\sigma_{x o}=E_{c j x}\left[\frac{e_{x o}+\mu_{c j y} e_{o y}}{1-\mu_{c j x} \mu_{c j y}}+T^{o}\left(\alpha_{j x T}+\mu_{c j y} \alpha_{j y T}\right)\right] .
$$


The stresses arising in the edges:

$$
\sigma_{x p}=E_{c j x}\left(e_{x p}+\alpha_{c j x} T^{o}\right) ; \quad \tau_{z x p}=\gamma_{k} G_{c j x} e_{z x} . \quad x \leftrightarrow y .
$$

Here, $\gamma_{\mathrm{k}}$ is the coefficient that takes into account the aspect ratio of the prismatic edge; $T^{o}=T^{o}\left(x, y, z\right.$, ) is the temperature; $G_{c j x}$ is the shear modulus; $E_{c j x}, E_{c j y}$ are the secant moduli of elasticity; $\mu_{c j x,}, \mu_{c j y}$ are the compressibility functions; $\alpha_{c j x,}, \alpha_{c j y}$ are the coefficient of linear expansion for the anisotropic material.

The coordinate functions for each individual panel are defined as the sum of two rows $[6,8,9]$ :

$$
U_{k}=\sum_{n}^{N} U_{o k}^{n} B_{k}^{(n)}+\sum_{n}^{N} U_{H k}^{n} Z_{j}^{(n)} ; V_{k}=\sum_{n}^{N} V_{o k}^{n} C_{k}^{(n)}+\sum_{n}^{N} V_{H k}^{n} Z_{j}^{(n)} ; W_{k}=\sum_{n}^{N} W_{o k}^{n} A_{k}^{(n)}+\sum_{n}^{N} W_{\mu k}^{n} Z_{j}^{(n)}
$$

Here, $N$ is the number of harmonics used in the expansion; $A_{k}, B_{k}, C_{k}, Z_{i}, Z_{j}$ are the variable parameters; $U_{о к,} V_{о к,} W_{о к,} U_{н \kappa}, V_{н \kappa}, W_{н \kappa}$ are the coordinate functions that satisfy the geometric boundary conditions at the edges of the $k$-th panel.

The oscillatory functions of the beams that satisfy the boundary conditions in the form of restraints are taken as components of the "homogeneous" series. The functions arising from the forced displacement of the edges along the nodal lines are taken as components of the "heterogeneous" series $[2,8]$. The proposed functions are written for each $k$-th panel.

Based on the main system and functional displacements, an expression for the energy functional of the system can be obtained in Lagrangian form:

$$
\delta \Phi=\delta \Pi-\delta A=0
$$

where $\Pi$ is the strain energy; $A$ is the external force energy.

By substituting the displacements into the strain expressions and then substituting the latter into the functional, we transform the energy of the system into a multi-parameter function.

Since the functional is cumbersome, the variable parameters can be found by one of the methods designed to search for unconditional extremum - the conjugate gradient method. The calculation algorithm is based on the method of successive approximation. The functional is minimized at each approximation step for a given load level and given boundary conditions. The variable parameters are found to determine displacements, strains, stresses, strain and stress rates.

\section{Testing of the Model}

According to the developed algorithm, we developed a design program in the Pascal algorithmic language and tested this program in a number of cases [9]. This paper presents a solution to one of the design problems - the determination of the stress-strain state of the flexible plate with initial deflection which is placed in a non-uniform temperature field and subject to elastic-plastic strains. Figure $2 a$ shows diagrams of additional deflections along the axis of symmetry at different temperatures $\left(t=20^{\circ} \mathrm{C} ; 100{ }^{\circ} \mathrm{C} ; 200{ }^{\circ} \mathrm{C}, 300{ }^{\circ} \mathrm{C} ; 400{ }^{\circ} \mathrm{C}\right)$. Due to the symmetry of the plate and the active temperature load, the diagrams are presented only for the left panel.

Figure $2 b$ shows diagrams of total deflections along the axis of symmetry, at different temperatures $\left(t=20^{\circ} \mathrm{C} ; 100^{\circ} \mathrm{C}-400^{\circ} \mathrm{C}\right)$. 


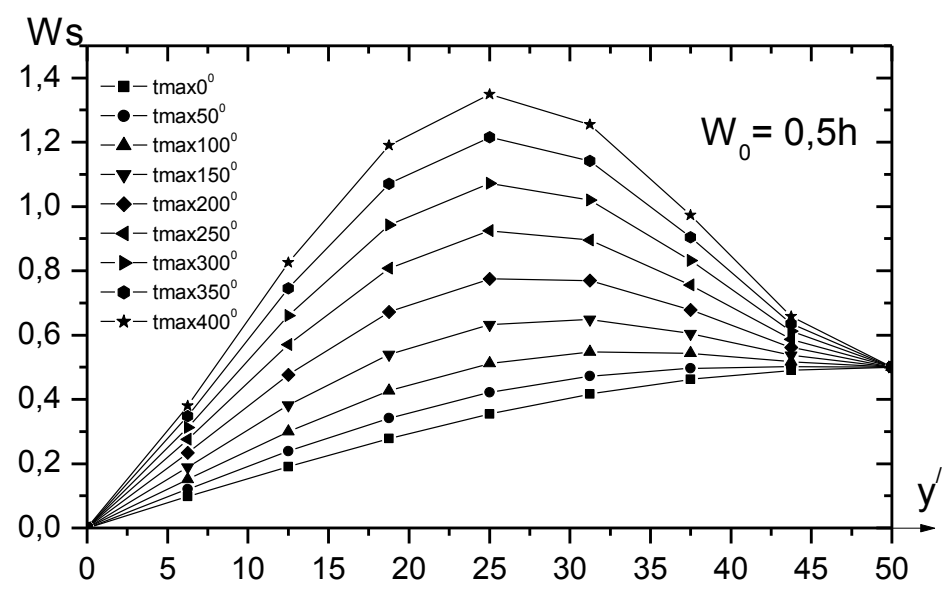

$a$

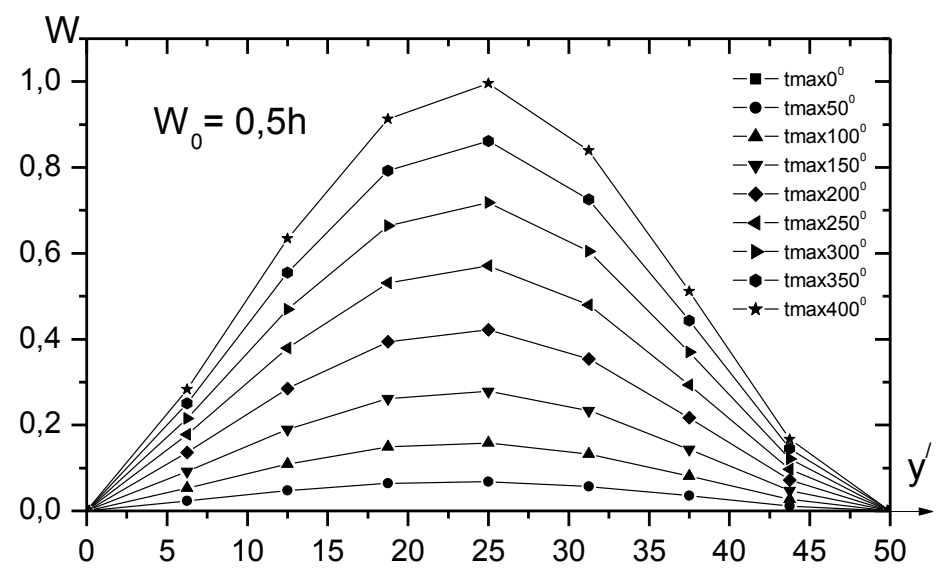

$b$

Fig. 2. Diagrams of total (a) and additional deflections (b) of the left panel with initial deflection, under exposure to different temperatures $W_{0}=0,5 h$.

Figure 3 presents diagrams of strain rates for upper fibers (Fig. $3 a$ ) and lower fibers (Fig. $3 b)$ of the left panel under exposure to different temperatures $\left(\mathrm{t}=20^{\circ} \mathrm{C} ; 100^{\circ} \mathrm{C}-\right.$ $\left.400^{\circ} \mathrm{C}\right)$. 


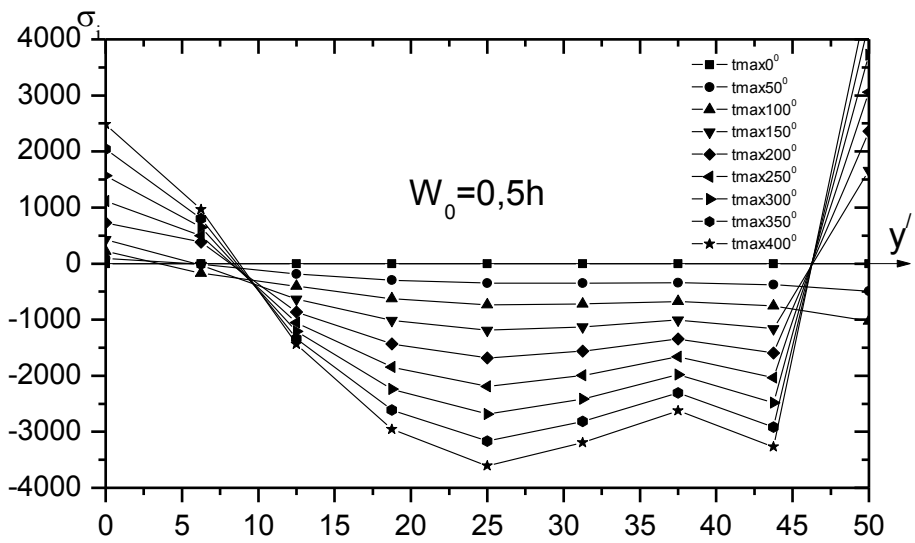

$a$

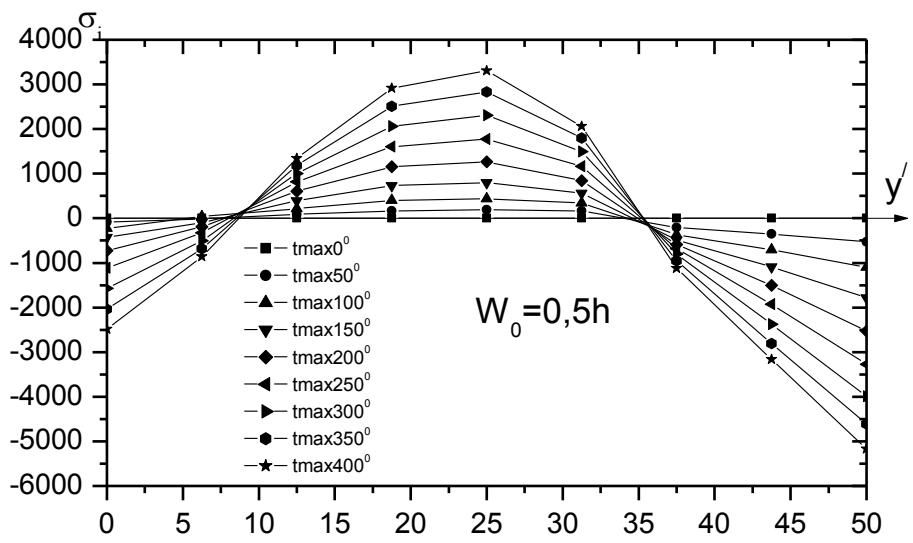

$b$

Fig. 3. Diagrams of strain rates for upper fibers (a) and lower fibers (b) of the left panel with initial deflection, under exposure to different temperatures $W_{0}=0,5 h$.

The design results for a two-field flexible plate with an initial deflection $\left(W_{0}=0,5 h\right)$ exposed to a non-uniform temperature field shows that additional total deflections and strain rates reach their maximum values in the center of the panel and increase with temperature. At $t=100{ }^{\circ} \mathrm{C}$, the difference between additional displacements of the panels with different initial deflections exceeds $100 \%$. As temperature increases, the difference decreases and, at $t=400{ }^{\circ} \mathrm{C}$, reaches $25.8 \%$.

\section{Conclusion}

The developed mathematical model for designing flexible plates with an initial deflection exposed to certain temperatures can be used to perform a comprehensive analysis of the stress-strain state and to estimate safety margin of flexible plates in terms of strength and rigidity. 
The further research should be aimed at developing an analytical model and a program for designing thin-walled structural elements with regard to mechanical compliance of the contour.

\section{References}

1. N.I. Bezuhov, V.L. Bazhanov, I.I. Gol'denblat, N.A. Nikolaenko, A.M. Sinjukov, Raschety na prochnost' ustojchivost' i kolebanija $\mathrm{v}$ uslovijah vysokih temperatur [Calculations for strength, stability and vibrations under high temperature conditions] (Mashinostroyeniye, Moscow, 1965) (in Russian)

2. V.V. Karpov, V.A. Mashkov, V.N. Filatov, Matematicheskoe modelirovanie, chislennye metody $i$ kompleksy programm [Mathematical modeling, numerical methods and software], 88-92 (1994)

3. V.P. Kruglov, News of higher educational institutions. Construction and Architecture, 6, 35-38 (1979)

4. A.G. Tamrazjan, A.S. Kozhanova, Promyshlennoe i grazhdanskoe stroitelstvo [Industrial and civil engineering ], 10, 15-20 (2015)

5. S.I. Trushin, Stroitel'naja mehanika: metod konechnyh jelementov [Structural mechanics: the finite element method] (INFRA-M, Moscow, 2016)

6. M.O. Moiseenko, A.P. Malinovsky, O.N. Popov, T.A. Treputneva, Proceedings of the Conference "Construction Science-XXI Century: Theory, Education, Practice, Innovation in the North-Arctic Region", 237-242 (2015)

7. A.V. Aleksandrov, B.Ya. Lashchenikov, N.N. Shaposhnikov, Stroitel'naja mehanika. Tonkostennye prostranstvennye sistemy [Structural mechanics. Thin-walled space systems] (Strojizdat, Moscow, 1983)

8. V.N. Zav'jalov, Trudy Tomsk. inzh.-stroit. in-ta: Issledovanija po stroitel'nym konstrukcijam [Reports of Tomsk Engineering and Construction Institute: Studies on building structures], 25-31 (1974) (in Russian)

9. O.N. Popov, A.P. Malinovskij, M.O. Moiseenko, Nelinejnye zadachi rebristyh obolochek [Nonlinear problems of ribbed shells] (Tomsk State University of Architecture and Building, Tomsk, 2004) (in Russian)

10. V.V. Petrov, I.G. Ovchinnikov, V.K. Inozemtsev, Deformirovanie elementov konstrukcij iz nelinejnogo raznomodul'nogo neodnorodnogo materiala [Deformation of structural elements from a non-linear, non-homogenous, inhomogeneous material] (Saratov State University, Saratov, 1989) (in Russian)

11. T.M. Pham, X. Lei, M.N.S. Hadi, Conference on the Mechanics of Structures and Materials (ACMSM22), 139-144 (Sydney, Australia, December 11-14, 2012)

12. Y. Zhang, D.G. Karr, Journal of structural engineering, 5, 04017003 (2017)

13. S.U. Bhat, S.K. Choi, T. Wierzbicki, D.G. Karr, Journal Offshore Mech. Arct. Eng., 113 (2), 171-178 (1991) 